\title{
Experiencias con infraestructuras y teletrabajo
}

\author{
PALOMA MARÍN-ARRAIZA \\ Engagement Lead para Europa en ORCID
}

Paloma Marín-Arraiza nos cuenta cómo llegó a trabajar en la Ciencia de la Información y más concretamente al trabajo con infraestructuras de información científica. Iniciando su andadura en la Biblioteca Nacional Alemana de Ciencia y Tecnología en el portal de vídeos científicos, donde aprendió el gran potencial de colaboración que tenían las Bibliotecas universitarias. De allí se fue a Brasil para realizar el doctorado, después a Austria para trabajar en la biblioteca universitaria de la Universidad Técnica de Viena. Y actualmente, trabaja en el equipo de ORCID.

Gestión de proyectos, Interoperabilidad, ORCID, Teletrabajo, Trabajo remoto, Identificadores de investigación.

Tras licenciarme en Física por la Universidad de Granada continué con un máster en Información y Comunicación Científica que me llevó luego a trabajar en el Biblioteca Nacional Alemana de Ciencia y Tecnología (TIB) en Hannover (Baja Sajonia).

Este fue realmente mi primer contacto con el mundo bibliotecario, pero desde la óptica de los materiales no textuales - yo trabajaba en el portal de vídeos científico, TIB $\mid$ AV-Portal一. En ese momento — no lo había hecho hasta entonces, ni durante mi etapa universitaria, mea culpa - me di cuenta del gran potencial de colaboración que tenían las bibliotecas universitarias y de investigación en el apoyo a la infraestructura de investigación.

Asimismo, se me presentó un panorama cambiante en cuanto a cómo se transmitía y diseminaba la información científica. Un artículo científico podía ir acompañado de un resumen en vídeo (conocidos como video abstracts) o incluir vídeos u otros materiales, textuales o no textuales, como suplemento. Esto facilitaría la comprensión y divulgación del artículo e, incluso, podría suponer un aumento en las citas del artículo.

Bajo el principio de que el acceso abierto a los resultados de investigación acelera el avance del conocimiento, todos los contenidos de la edición electrónica de CLIP se distribuyen bajo una licencia de uso y distribución Creative Commons Reconocimiento-NoComercialCompartirlgual 3.0 España (CC BY-NC-SA 3.0 ES). 


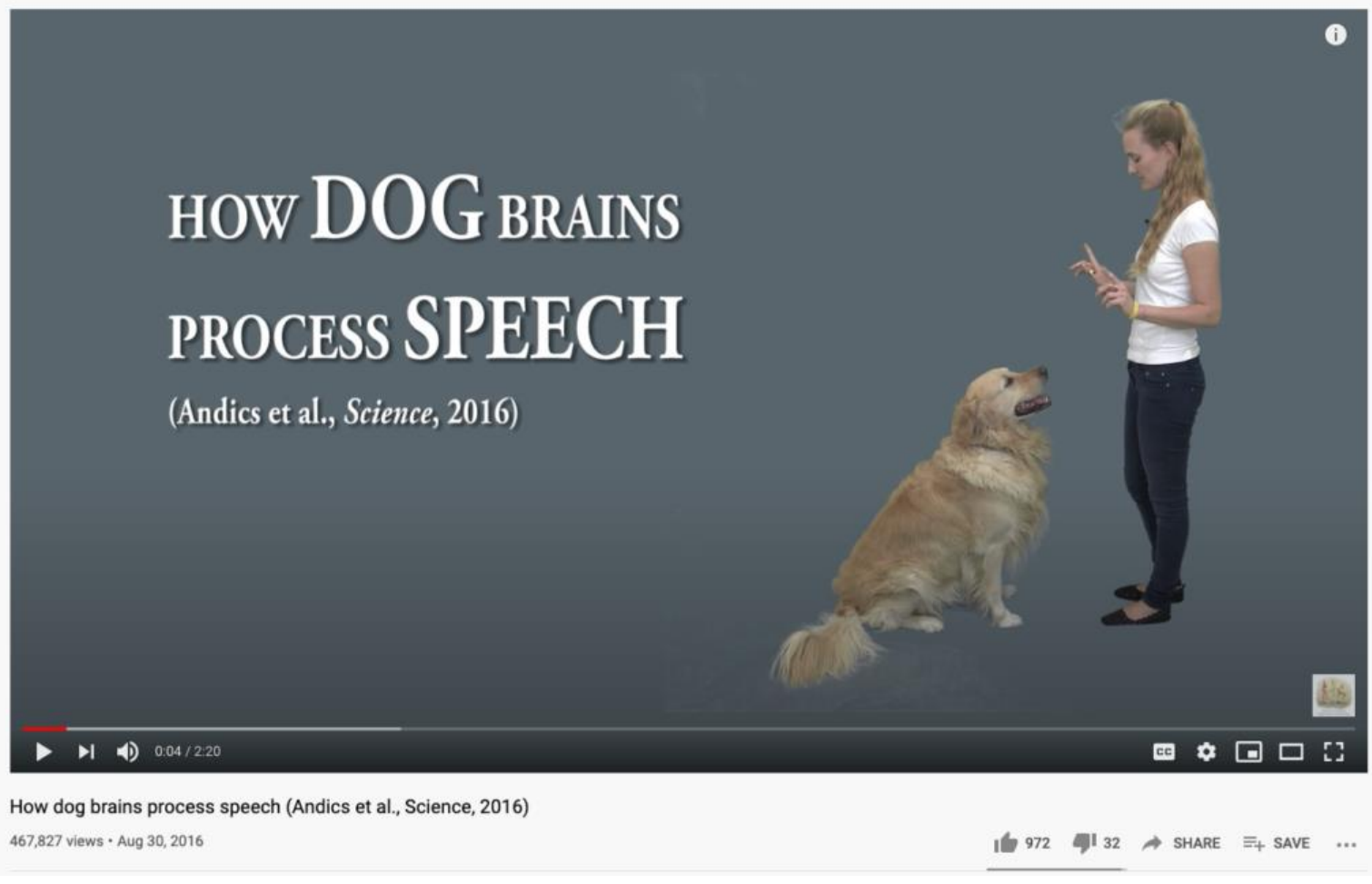

Figure 1: Ejemplo de un video abstract y su correspondiente artículo.

A su vez, cada uno de estos materiales estaba identificado de forma persistente, lo que lo convertía en una entidad independiente y citable dentro del ecosistema de investigación.

Como os podéis imaginar, mi mente en ese momento no paraba y estaba fascinada con cada uno de los detalles que iba descubriendo y con esta forma de entender la comunicación científica. Tanto es así que acabé doctorándome con una tesis sobre "publicación ampliada".

He de decir que profesionalmente he sido bastante nómada. Empecé trabajando en Alemania, me mudé a Brasil para realizar mi doctorado, después a Austria para trabajar en la biblioteca universitaria de la Universidad Técnica de Viena (TU Wien) y, finalmente este año, me incorporé al equipo de $\underline{\text { ORCID, }}$ lo que me permitió volverme a vivir a España.

En esta última fase, o en el puente entre la TU Wien y ORCID, tuve la posibilidad de participar en el programa de mentoría de SEDIC, lo que, sin duda, me aportó una visión mucho más amplia del trabajo en gestión de proyectos. Mi mentora y yo tuvimos la posibilidad de intercambiar muchas ideas al respecto y adaptarnos al trabajo mentora-mentorizada de forma virtual.

Pero, para no desviarnos del tema, ¿cuál es la conexión entre las diferentes tareas que he ido desarrollando profesionalmente? La respuesta es directa: las infraestructuras de investigación y los identificadores persistentes. Estos identificadores convierten a las entidades del ecosistema de investigación en entidades independientes, unívocamente identificadas y fácilmente referenciables.

Además, ¿qué otro aspecto nos interesa? Que haya una interoperabilidad entre los datos asociados a cada una de estas entidades. A eso precisamente dedico una parte muy importante de tiempo dentro de ORCID. Por otro lado, considero que las bibliotecas tienen un papel fundamental en el apoyo a esta interoperabilidad y en el fomento de infraestructuras abiertas. De hecho, en estos meses de pandemia en los que, desde ORCID, hemos realizado varias formaciones (mediante seminarios en línea) sobre el tema, he podido comprobar que el porcentaje más alto de participación venía de personal de bibliotecas y apoyo a la investigación (en CRAIs, etc.). 


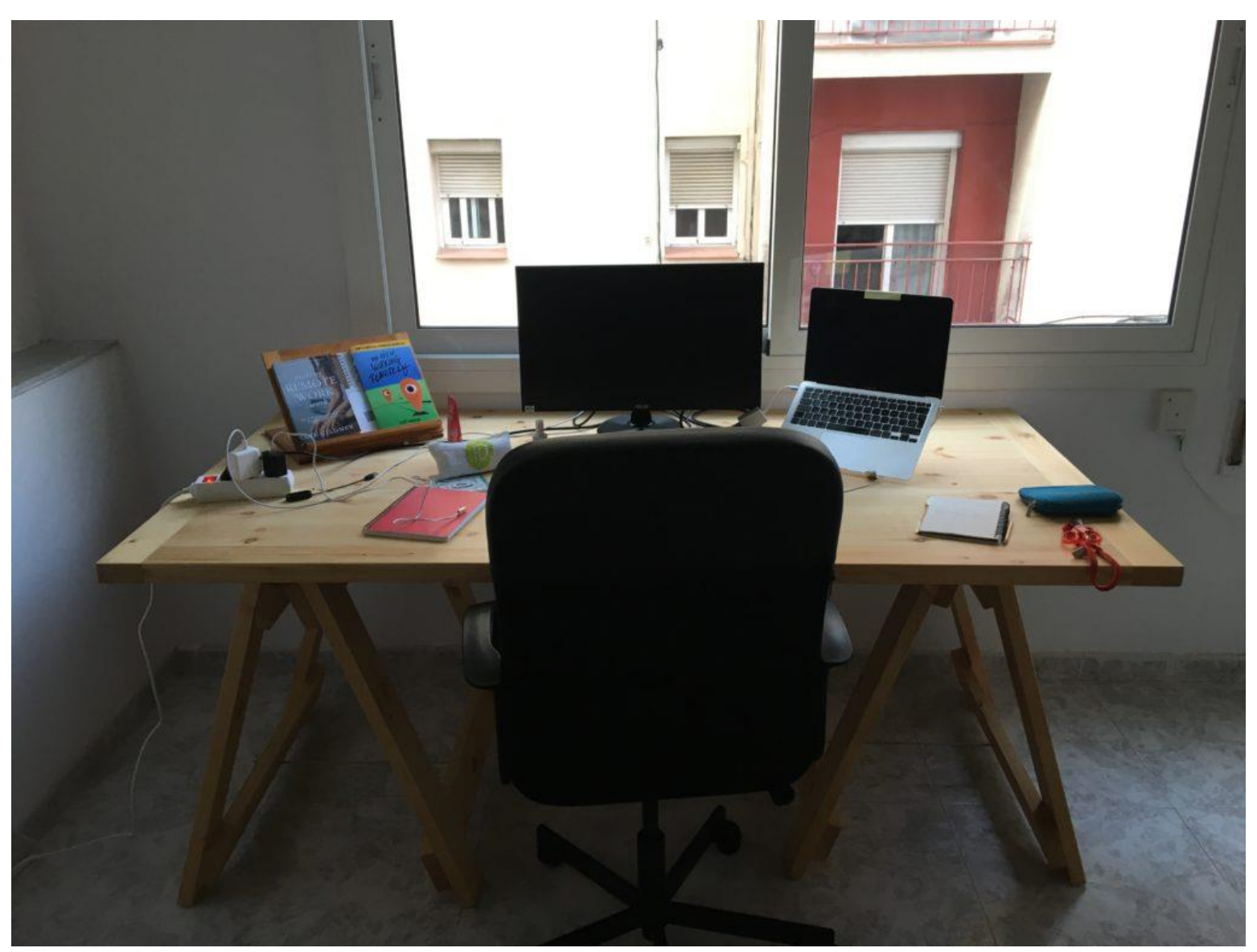

Figura 2: Mi "local de trabajo"

No podría concluir esta experiencia sin hilar con la situación que estamos viviendo en 2020: la pandemia de la COVID-19.

Empecé a trabajar en ORCID exactamente una semana después de que la pandemia fuese declarada. ORCID desde sus orígenes ha sido una organización virtual y descentralizada —el equipo está esparcido por diferentes países y usos horarios-; no obstante, nunca se había vivido el teletrabajo forzado por una pandemia.

Esta situación ha cambiado los flujos de trabajo y las formas de relacionarnos. En muchos centros de trabajo, ha generado al mismo tiempo confianza y desconfianza en cómo los demás están realizando sus tareas, así como eficiencia y sobrecarga (todos hemos oído hablar de la fatiga de Zoom). Al final, lo más difícil es definir límites claros entre lo que es la jornada y el espacio de trabajo y lo que es la vida personal y el descanso. La revista satírica The New Yorker lo ilustraba de forma muy acertada en una viñeta que decía "¿Trabajo en casa o vivo en el trabajo?".

Mi tiempo de trabajo en ORCID me está sirviendo para entender mucho mejor las dinámicas del trabajo remoto, incluir en mi día a día herramientas de trabajo colaborativo y entender que la respuesta de mis compañeros no tiene que ser inmediata, es más, probablemente, por diferencias horarias no lo sea.

Con todo lo anterior, me gustaría concluir recomendando los libros que, seguramente, sean de utilidad en la adaptación a esta nueva situación de virtualidad o semipresencialidad que ha llegado para quedarse con nosotros por un tiempo. 


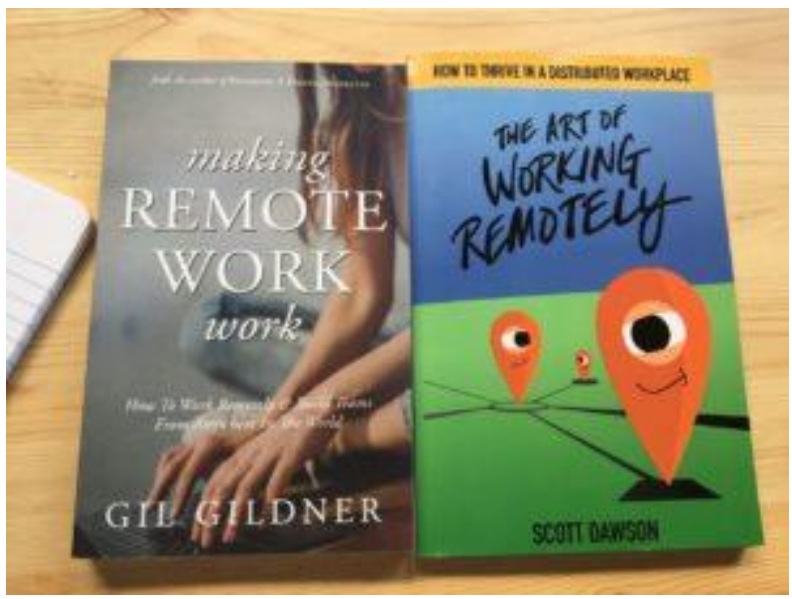

- Dawson, Scott. (2019). The art of working remotely. How to thrive in a distributed workplace. Knight Rose Press.

- Gildner, Gil. (2020). Making remote work work. How to work remotely and build teams from anywhere in the world. Baltika Press.

\section{Autora}

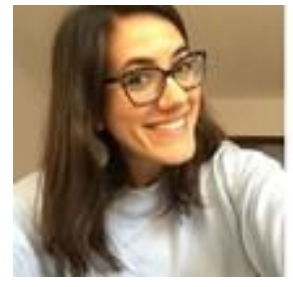

PALOMA MARÍN-ARRAIZA

Engagement Lead para Europa en ORCID

- Twitter: @pmarrai 